\title{
WLB in Zahlen 2011
}

\begin{tabular}{|c|c|}
\hline Gesamtbestand (Stand: 6.3.2012) & \\
\hline Medienbestand insgesamt & 5.737 .803 \\
\hline davon: & \\
\hline Buchmaterialien & 3.760 .698 \\
\hline Autographen & 180.439 \\
\hline Handschriften & 15.420 \\
\hline Inkunabeln & 7.087 \\
\hline Noten & 69.927 \\
\hline Karten & 151.829 \\
\hline Mikroformen & 471.482 \\
\hline AV-Materialien (Ton-, Bildträger) & 42.276 \\
\hline CD-ROMS & 20.714 \\
\hline Flugblätter & 159.290 \\
\hline Fotos & 577.065 \\
\hline Plakate & 39.739 \\
\hline Feldpostbriefe & 126.887 \\
\hline Porträts & 36.901 \\
\hline $\begin{array}{l}\text { Sonstiges davon: Varia 3.357, Disketten 3.391, Ortsansichten 8.262, Ansichtskarten 35.848, Ereignisdarstellungen 2.000, } \\
\text { Slg. Nicolai 22.000, Einblattmat./Sonstige 3.034, Nachlässe 157 }\end{array}$ & 78.049 \\
\hline Bibeln (in 639 Sprachen) & 19.472 \\
\hline Lfd. geh. Zeitschriften u. Zeitungen (Abos) & 12.147 \\
\hline Angebot an elektronischen Zeitschriften & 20.107 \\
\hline Angebot an online-Datenbanken & 255 \\
\hline Zugang 2011 & 94.331 \\
\hline Kauf & 25.458 \\
\hline Pflicht & 28.926 \\
\hline Tausch & 613 \\
\hline Geschenk (darin: 28.724 Mikrofiches) & 39.334 \\
\hline Benutzung 2011 & \\
\hline Öffnungstage & 293 \\
\hline Öffnungsstunden pro Woche & 64 \\
\hline Entleihungen insgesamt & 1.311 .111 \\
\hline Aktive Benutzer/innen & 33.098 \\
\hline Benutzer in den Lesesälen & 298.722 \\
\hline Benutzerschulungen / Führungen (Stunden) & 366 \\
\hline Fernleihbestellungen (aktiv, pos. erledigt) & 42.309 \\
\hline Fernleihbestellungen (passiv, pos. erledigt) & 20.347 \\
\hline Direktlieferdienste & 30.854 \\
\hline Personalstellen 2011 & 127 \\
\hline Kulturelle Veranstaltungen 2011 & 34 \\
\hline Ausstellungen & 8 \\
\hline Weitere Veranstaltungen & 26 \\
\hline
\end{tabular}

